\title{
Ecosystem Vulnerability Review: Proposal of an Interdisciplinary Ecosystem Assessment Approach
}

\author{
Peter Weißhuhn $\mathbb{D}^{1} \cdot$ Felix Müller $^{2} \cdot$ Hubert Wiggering $^{3}$
}

Received: 21 June 2017 / Accepted: 1 March 2018 / Published online: 14 March 2018

(c) The Author(s) 2018. This article is an open access publication

\begin{abstract}
To safeguard the sustainable use of ecosystems and their services, early detection of potentially damaging changes in functional capabilities is needed. To support a proper ecosystem management, the analysis of an ecosystem's vulnerability provide information on its weaknesses as well as on its capacity to recover after suffering an impact. However, the application of the vulnerability concept to ecosystems is still an emerging topic. After providing background on the vulnerability concept, we summarize existing ecosystem vulnerability research on the basis of a systematic literature review with a special focus on ecosystem type, disciplinary background, and more detailed definition of the ecosystem vulnerability components. Using the Web of Science ${ }^{\mathrm{TM}}$ Core Collection, we overviewed the literature from 1991 onwards but used the 5 years from 2011 to 2015 for an in-depth analysis, including 129 articles. We found that ecosystem vulnerability analysis has been applied most notably in conservation biology, climate change research, and ecological risk assessments, pinpointing a limited spreading across the environmental sciences. It occurred primarily within marine and freshwater ecosystems. To avoid confusion, we recommend using the unambiguous term ecosystem vulnerability rather than ecological, environmental, population, or community vulnerability. Further, common ground has been identified, on which to define the ecosystem vulnerability components exposure, sensitivity, and adaptive capacity. We propose a framework for ecosystem assessments that coherently connects the concepts of vulnerability, resilience, and adaptability as different ecosystem responses. A short outlook on the possible operationalization of the concept by ecosystem vulnerabilty indices, and a conclusion section complete the review.
\end{abstract}

Keywords Environmental vulnerability $\cdot$ Ecological vulnerability $\cdot$ Ecosystem response $\cdot$ Interdisciplinarity $\cdot$ Resilience $\cdot$ Adaptability

\section{Introduction}

Ecosystem services sustain and fulfill several demands of human life but rely on ecosystem processes and associated species (Daily 1997). A sustainable use of ecosystems implies a balance between protection and exploitation. Because ecosystems are defined by a close functional

Peter Weißhuhn

weisshuhn@zalf.de

1 Leibniz Centre for Agricultural Landscape Research (ZALF) e.V., Eberswalder Straße 84, 15374 Müncheberg, Germany

2 Institute for Natural Resource Conservation, Kiel University, Olshausenstraße 40, 24098 Kiel, Germany

3 Institute of Earth and Environmental Science, University of Potsdam, Karl-Liebknecht-Straße 24/25, 14476

Potsdam, Germany interconnection between their constituting abiotic and biotic elements, any use will change their conditions. Therefore, a condensed measure to assess the potential damage to ecosystems' structures and functionalities, as well as their capacities to recover, ahead of the change would help achieve such a balance.

A vulnerability analysis is an adequate method for understanding the weaknesses of a system and is strictly orientated towards the threat that potentially would harm the system (Wisner et al. 2004). In general, vulnerability is defined as the potential for loss (Adger 2006; Brooks 2003; Füssel 2007; IPCC 2014), but rarely has been transferred for application to ecosystems. An ecosystem vulnerability assessment could be used to estimate the inability of an ecosystem to tolerate stressors over time and space (Williams and Kapustka 2000). Those vulnerable ecosystems then would need a proper management to preserve their characteristics. Any kind of ecosystem management is a result of governance processes responding to ecological, 
socio-cultural and economic drivers (Simoncini 2011) and aims to maintain desirable levels of ecosystem function in a cost-effective and socially responsible manner (Brussard et al. 1998). It is called ecosystem-based management because it recognizes all interactions within an ecosystem, including humans (Leslie and McLeod 2007). Slocombe (1993) summarizes that ecosystem-based management is a matter of redefining management units and building on scientific knowledge on the biophysical resource use limits. Available measures for ecosystem management are to reduce local and regional stressors, designate protected areas as refuges (Okey et al. 2015), increase ecosystem resilience (e.g., Anthony et al. 2015), or involve the implementation of other conservation strategies specific to each ecoregion (cf. Watson et al. 2013).

To communicate the results of vulnerability assessments to other researchers, policy-makers, and the community at large, it is important to map vulnerability distributions (Eakin and Luers 2006), and therefore to be spatially explicit. The mapping could indicate ecosystem vulnerability hotspots that may require specific intervention of protection and maintenance (Aretano et al. 2015; Zurlini et al. 1999). So far, there are limited successful ecosystem vulnerability studies focusing on the management of natural areas or conservation (Ventura and Lana 2014), but socioenvironmental studies have been undertaken longer (Villa and McLeod 2002).

Next to its application benefit for ecosystem management purposes, the concept also bears potentials for theoretical progress. To further shape the definition of ecosystem vulnerability and to investigate its relation to other theoretical concepts from ecology, will contribute to develop vulnerability towards a boundary object (cf. Collet 2012). Boundary objects could steer interdisciplinary research that seems indispensable to tackle the-typically complexresearch questions related to ecosystem management or socio-ecological systems.

This review is structured according to four main objectives: (i) to provide background on the vulnerability concept; (ii) to summarize existing ecosystem vulnerability research with a special focus on ecosystem type, disciplinary background, and definition of the ecosystem vulnerability components; (iii) to place ecosystem vulnerability in coherence with the ecological concepts of resilience and adaptability, and (iv) to give a short overview on ecosystem vulnerability assessment methods ready for application.

\section{Background: The Vulnerability Concept}

The idea of vulnerability is based on research on natural hazards affecting human structures and communities (Janssen et al. 2006). This introduced an objectivist understanding of risk to the concept, which has been revised by the argument of risk as a matter of perception (Bürkner 2010; Weichselgartner 2001). For the analysis of social systems, the emphasis on a system's weakness is prone to criticism, as different social groups could be stigmatized, for example, regarding gender, income, educational level, or ethnicity (Bürkner 2010; Collet 2012). In the vulnerability of social-environmental systems, Eakin and Luers (2006) traced down the scientific roots to the three research fields of risk-hazard, political economy/political ecology, and ecological resilience. Two major antecedents for a shared definition of vulnerability are the risk-hazard and the pressure-and-release model (cf. Turner et al. (2003)). Riskhazard models emphasize exposure and sensitivity to perturbations and stressors forming the impact of the hazard; and pressure-and-release models emphasize distinctions in risk related to different vulnerabilities of different exposure units, while both underemphasize the system's ability to cope with the disaster and learning from it (ibid.). This lead to the idea of adaptive capacity, which conceptually could link vulnerability and resilience research, and turned vulnerability assessments to the purpose of identifying feasible adaptation strategies (Engle 2011; Smit and Wandel 2006).

Interdisciplinary vulnerability concepts mainly developed with climate change research and its increasingly broad applications (e.g., IPCC 2007; IPCC 2014). Related to this, global environmental change research also has seen increased attention to the concept of vulnerability (Polsky et al. 2007; Schröter et al. 2005). A general uniform definition has been lacking for a long time (Brooks 2003) because several scientific disciplines have emphasized and advanced different scientific aspects of vulnerability research (Schluchter 2002). Nevertheless, an overarching definition would describe vulnerability as a potential for loss (Adger 2006; Brooks 2003; Füssel 2007; IPCC 2014). Further, several systematic attempts to establish an interdisciplinary methodological framework for vulnerability research outlined vulnerability as a function of exposure, sensitivity, and adaptive capacity (Frazier et al. 2014; Füssel 2007; Turner et al. 2003). According to the state of the art, we further define vulnerability by its three constituting elements as follows:

- "exposure" describes the probability of a hazard (also: disturbance or stress) occurring;

- "sensitivity" is a measure of susceptibility to this hazard;

- "adaptive capacity" characterizes the ability to cope with the hazard and its consequences.

In this context, we suggest vulnerability as a boundary object, as it enables interdisciplinary scientific exchange without abandoning a specialist's inventory of methods (Collet 2012). Typically, a vulnerability analysis integrates 
different methods from across several research traditions (Polsky et al. 2007).

A more recent and specific notion of vulnerability, but one consistent with the general framework, is ecosystem vulnerability. In this perspective an environmental system moves from a traditional view as a source of hazard that influences human systems to a responding system influenced by natural and anthropogenic drivers of change. Birkmann and Wisner (2006) called this a biocentric view of ecological vulnerability, in contrast to an anthropocentric view. It encompasses the analysis of the fragility and susceptibility of ecosystem components or functions themselves. A very prominent initiative for such an approach is the Environmental Vulnerability Index developed by the South Pacific Applied Geoscience Commission in cooperation with the United Nations Environment Program. This index is based on 50 indicators for estimating a general vulnerability of the environment to future shocks, calculated for each country on the globe (Kaly et al. 2004).

\section{Methods}

This review analyzes the emerging concept of ecosystem vulnerability and is based on a literature search in the Web of Science ${ }^{T M}$ Core Collection (enabling the following databases: SCI-EXPANDED, SSCI, CPCI-S, CPCI-SSH, BKCI-S, and BKCI-SSH). First, a title search provided descriptive overview on the development of the different terms connected with the vulnerability of natural systems (this section). Second, the main search covered the title, abstract, author keywords and keywords plus ${ }^{\circledR}$ and provided the literature sample for the structured review (following sections).

To support a conceptual analysis, the literature search was designed to focus on scientific articles that explicitly refer to the vulnerability concept, recognizing this would exclude literature on "resilience", "risk", "damage", "degradation", or "change" that may be related to the discussion on ecosystem vulnerability. To cover the broad disciplinary roots of a vulnerability analysis of natural systems, the search included the terms "ecosystem vulnerability", "ecological vulnerability", and "environmental vulnerability". We aimed to cover vulnerability research on several ecological scales and therefore considered the vulnerability of populations, communities, and habitats. Unfortunately, the term "community vulnerability" turned out to be unsuitable, as very few related to ecological communities, with the others relating to human communities. Therefore, we only added "population vulnerability" and "habitat vulnerability" to the query, which connected the exact terms with OR and was last updated on June 22nd, 2016.

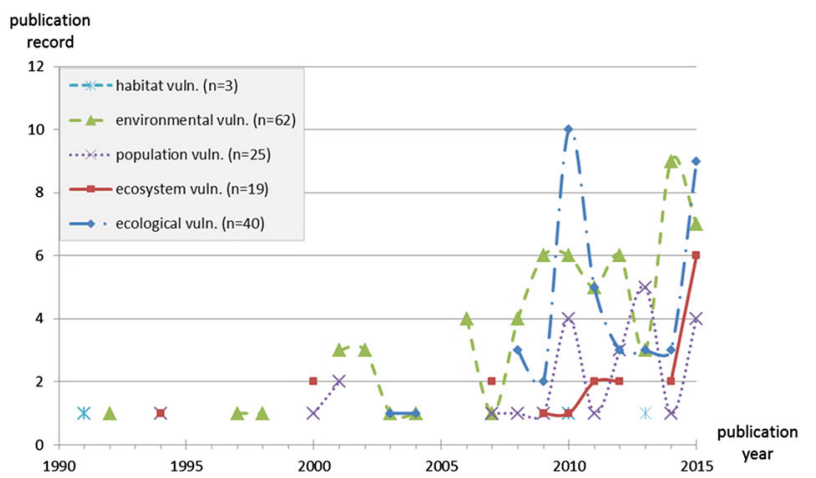

Fig. 1 A temporal overview of the use of different vulnerability terms in the publication title $(n=149)$. All terms conceptualize natural systems as more or less vulnerable

For overviewing the usage of the vulnerability concept applied to ecosystems research, we started to search the publication title over 25 years, from the beginning of 1991 to the end of 2015, and itemized the different terms (see Fig. 1). Note that articles including socio-ecological vulnerability were also covered, but these comprised only $5 \%$ of the results returned due to the term "ecological vulnerability".

In our sample of 149 papers ranging from 1991 to 2015, the term habitat vulnerability occurred earliest, but with only three articles; it appears to be rather unestablished. In the nineties, the terms environmental and ecosystem vulnerability arose. While environmental vulnerability gained remarkable attention from 2009 onwards and exhibited the most applications over the entire period, the use of the term ecosystem vulnerability only caught on very recently. In our sample, the term ecological vulnerability occurred late, first in 2003, but its use increased sharply in 2010, reaching a total maximum of 10 articles in a year. The term population vulnerability varied between 5 and only 1 title mention per year; therefore, this term seems to not play a major role in this research field, yet.

For the main search, the same five vulnerability terms were applied to TOPIC. To cover the period of increased interest in the concept from 2010 onwards (indicated by the annual number of publications constantly exceeding 10 , see Fig. 1) and to reach an adequate number of articles for indepth analysis, we limited our literature to the five years from 2011 to end of 2015 while excluding all document types other than articles and reviews in English. The resulting 238 articles we filtered by abstract reading to sort out any artifact items and articles not related to the vulnerability of natural systems (e.g., public health vulnerability). During this process, we found the term "population vulnerability" repeatedly used to refer to human populations instead of natural populations (species or species assemblages) and "environmental vulnerability" used, to a minor extent, to refer to psychological phenomena. Furthermore, 
we identified some articles using "environmental vulnerability" as a combination of both biophysical and socioeconomic factors that affect a human-natural system. Because such an understanding of environmental vulnerability does not focus on ecosystems as the responding system (cf. "Background: the Vulnerability Concept" section), these were also omitted. Overall, 129 articles were reviewed. Additionally, for the three sections prior to 'Conclusions' other thematic leading publications (e.g., published before 2011 or not in the Core Collection) were considered to give a comprehensive picture.

For the analysis of the investigated ecosystem type and disciplinary roots (cf. next section), we decided to cite references exemplarily if the number of articles belonging to one group was too high to cite all of them. To safeguard reproducibility, we cited the top three articles ranked by the SJR index (SCImago 2007) from their publishing journal in the publication year of the article, and as a secondary criteria, we selected the most recent article. To give a diverse picture, we did not choose two articles from the same journal.

\section{Vulnerability of Different Ecosystems and in Different Disciplines}

To reach a profound understanding of the concept of ecosystem vulnerability, which is necessary to provide a so far lacking comprehensive and in-depth definition, the disciplinary roots may reveal characteristic orientations. A too narrow scope in the major application areas (in the sense of the natural systems under investigation) could have biased the conceptual development or identify gaps in ecosystem vulnerability research. Therefore, we also paid attention to the type of ecosystem that has been assessed.

More than half of the 129 reviewed ecosystem vulnerability studies apply to a certain type of ecosystem (for an overview, see Table 1). These 72 articles exhibited a major focus on water-related ecosystems: marine and coastal ecosystems (including mangroves) accounted for 30 papers (e.g. Anthony et al. 2015; Guizien et al. 2014; Ifrim et al.

Table 1 Focus ecosystems of the reviewed vulnerability studies $(n=129)$

\begin{tabular}{ll}
\hline Focus ecosystem & Number of articles \\
\hline Marine and coastal ecosystems & 30 \\
Freshwater ecosystems & 22 \\
Forest ecosystems & 13 \\
Grassland and agricultural ecosystems & 4 \\
Desert and oasis ecosystems & 3 \\
No particular ecosystem mentioned & 57 \\
\hline
\end{tabular}

2011) and freshwater ecosystems (including rivers, lakes, and wetlands), accounted for 22 papers (e.g., Alric et al. 2013; Landguth et al. 2014; Macary et al. 2014). Another focus was also given to forest ecosystems (e.g., Hwang et al. 2014; McWethy et al. 2013; Zolkos et al. 2015). Only three articles dealt with grassland ecosystems (Lopez-Poma et al. 2014; Qiao et al. 2013; Ursino 2014), and only one was concerned with agricultural ecosystems (Couto et al. 2015). Additional two articles were concerned with desert ecosystems (Cruz-Elizalde et al. 2014; Munson et al. 2015) and one with an oasis (Pei et al. 2015). The other 57 articles involved vulnerability analysis at a different kind of spatial scale, for example, administrative regions, river-basins, or climatic zones.

Observing the (explicitly stated) disciplinary origin of the articles was the task to identify the main scientific communities that promote the concept of ecosystem vulnerability. Note that each article potentially belonged to more than one research field.

A total of 54 of the reviewed articles were strongly linked to conservation ecology $(\approx 42 \%)$. Of these, 29 articles addressed a wide range of particular species: ten articles focused on aquatic species (e.g., Ateweberhan et al. 2011; Guizien et al. 2014; Landguth et al. 2014), nine on plant species (e.g., Arianoutsou et al. 2013; Gonzalez-Moreno et al. 2013; Kalusova et al. 2013), five on bird or bat species (e.g., Erickson et al. 2015; Furness et al. 2012; Tranquilla et al. 2013) and five on other animal species (e.g., Drever et al. 2012; Dufresnes and Perrin 2015; Lacasella et al. 2015). Furthermore, 15 addressed whole habitats (e.g., Gauthier et al. 2013; Giakoumi et al. 2015; Kalusova et al. 2013), and four focused on the vulnerability of the protected area itself (e.g., Aretano et al. 2015; Cruz-Elizalde et al. 2015; Tomczyk 2011). Eight of the 54 articles related to conservation ecology investigated the vulnerability to invasive species (e.g., Hulme 2012; Kalusova et al. 2013; Olden et al. 2011). Further, from an ecological and evolutionary perspective, Diaz et al. (2013) framed response functions opposed to specific effect functions of certain species for vulnerability analysis of ecosystem services.

Ecosystems and geographic regions were classified as vulnerable to climate change in the latest IPCC Assessment Report (IPCC 2014). A reference to the vulnerability of ecological systems to climate change could be found in 30 studies $(\approx 23 \%)$; of these, 8 were in connection with nature conservation. Beyond our literature sample, we found that ecosystem vulnerability to climate change is commonly analyzed by using ecological response models (NWF 2011) and climate adaptation of ecosystems is implemented via the so-called MARISCO approach (Ibisch and Hobson 2014, for example).

An ecosystem-related concept of vulnerability was also discussed in ecotoxicology (De Lange et al. 2010), 
particularly in the context of ecological risk assessment (ERA), which is conceptually close to ecosystem vulnerability (Chen et al. 2013). In our literature sample, we found 21 articles attributable to ERA $(\approx 16 \%)$. An additional paper dealt with contamination in a regional risk assessment (Zabeo et al. 2011). The ERAs were applied to aquatic ecosystems (e.g., Agatz et al. 2012; Gergs et al. 2013; Kulkarni et al. 2014), and fewer addressed contamination of the soil (e.g., Couto et al. 2015; Pinedo et al. 2014; van Gestel 2012) or groundwater (Caniani et al. 2015).

To a minor extent, landscape ecology was present (12 articles), often in connection with fire regimes. The remaining articles, which have not been assigned to any of the aforementioned disciplinary groups $(\approx 25 \%)$, rather occasionally shared a common research area. They often addressed ecosystem vulnerability to multiple environmental changes and included a strong integrated management orientation (e.g., oil pollution management). Other related research fields expected to be found explicitly, like restoration ecology (5 articles), environmental impact assessment (3 articles), ecosystem-based management (1 article), and natural resource management (no article), so far seemed not to have substantially adopted the concept of ecosystem vulnerability.

\section{Defining Ecosystem Exposure, Sensitivity, and Adaptive Capacity}

The application of the vulnerability concept generally has been approached through its three components: exposure, sensitivity, and adaptive capacity. Nevertheless, our review identified rather diverse or incomplete definitions of ecosystem exposure, ecosystem sensitivity, and ecosystem adaptive capacity. Understandably, the formative influences, from several research traditions (cf. "Background: the Vulnerability Concept" section), coined different meanings of ecosystem vulnerability. Therefore, we furthered the application of the concept by delivering a clear and general description of the meanings of ecosystem exposure, ecosystem sensitivity and ecosystem adaptive capacity. We paid heed to a common understanding of the three elements of ecosystem vulnerability, which were often-but not always-mentioned implicitly only.

\section{Exposure of Ecosystems}

The exposure of an ecosystem expresses the degree of change that it is projected to experience (e.g., Cabral et al. 2015; Zolkos et al. 2015). According to the abruptness of the change, the terms disturbance (abrupt) and stress (continuous) can be distinguished. A disturbance or shock could have consequences of similar severity for an ecosystem as an enduring or increasing stress perceived as nearing a threshold or tipping point (Redman 2014). Examples in our literature sample of these exposures were effects of climate change (e.g., Moe et al. 2013; Okey et al. 2015), land use changes like deforestation or urbanization (e.g., Ventura and Lana 2014), invasive species (e.g., Arianoutsou et al. 2013; Olden et al. 2011), and effects from pesticides (van Gestel 2012), oil spill (Cai et al. 2015) or other toxicants (e.g., Vigneron et al. 2015). According to Ippolito et al. (2010), the different stressors should be addressed by single and separate vulnerability assessments as long as the combining effects and interrelations are not yet fully understood. Nevertheless, unassessed stressors are present and could influence the investigated vulnerability and combining effects may show most relevance to ecosystem management. For example, Agatz et al. (2012) investigated the combined effects of different chemicals on Daphnia magna populations, and Alric et al. (2013) combined climate warming with changes in nutrient inputs and fisheries management practices for lake ecosystems.

With regard to the term "disturbance", we adhere to the absolute definition (in contrast to relative disturbance). According to this definition, disturbances can be determined as directly measurable changes in an ecosystem and are independent of statistical distribution, a recurrence period or predictability that would define a relative disturbance. White and Jentsch (2001) described the properties of disturbances, of which those deriving from exogenous factors were assigned as features of exposure. These are, on the one hand, the expansion and spatial distribution of disturbance (in relation to ecosystem size or ecosystem heterogeneity) and, on the other hand, the duration and frequency of the disturbance (in relation to ecosystem lifespan or recovery time). To assess the exposure of an ecosystem, the probability of a disturbance or spatial proximity to a disturbance source could guide the analysis (Frazier et al. 2014). Another option is to analyze the amount of (spatially located) system elements that are affected by a given disturbance. For example, this could mean determining the area of the ecosystem under threat (Dong et al. 2015).

\section{Sensitivity of Ecosystems}

Given a certain disturbance or stress, sensitivity describes the susceptibility of the ecosystem. It expresses the degree to which a system is likely to be affected by or be responsive to the change (cf. Zolkos et al. 2015) and could tell us about the expected severity of the impact. A longterm exposure to one stress may lead to the development of increased tolerance (or decrease in sensitivity), but potentially increases the vulnerability to other environmental changes. This could mean, for example, that according to 
micro-evolutionary processes the resulting population, which successfully survived a first stress from a toxicant, is less competitive for foraging and likely to be more affected to another stress like a nourishment-poor period (Vigneron et al. 2015). The sensitivity could be determined by specific indicators according to the ecosystem and exposure under investigation. Illustrative factors from our literature sample were, for instance, the elevation of coastal wetlands exposed to sea level rise (Chu-Agor et al. 2011), for river ecosystems under climate change the amount of flow (Abbasov and Smakhtin 2012) or resistance of water temperature to air temperature increase (Trumbo et al. 2014), the chemical susceptibility of freshwater ecosystems to toxicants (Ippolito et al. 2012), and abundance of habitat loss-sensitive fish species (compared to more generalist species) for a coral ecosystem exposed to bleaching (Cinner et al. 2013).

In contrast to exogenous disturbance factors, intensity and specificity are endogenous disturbance factors and are defined by the inherent properties of the ecosystem. However, these properties are hardly measured by holistic ecosystem indicators so far. Therefore, many aspects of ecosystem sensitivity are derived from the inherent characteristics of species (NWF 2011). For example, differences in sensitivity to environmental influences between functionally similar species stabilize ecosystem processes and related services. In contrast, if these differences exist predominantly between functionally differing species, an ecosystem tends to be more vulnerable to changes (Chapin et al. 1997). In conservation ecology this is referred to as species redundancy within functional groups (Rosenfeld 2002; Walker 1992).

In the context of human dependency on ecosystems and the consequences of a potentially dramatic decline in ecosystem services, it seems conceivable to view particular important ecosystems as high-reliability systems. The importance of an ecosystem could be derived from its relevance for water supply (local importance), food provision (e.g., regional importance), carbon sequestration (global importance), or any other ecosystem service that is hard to do without in a specific context. This borrowing from sociological technology studies implies that efficiency and profit maximization should be subordinate to the reliability of the system (Kaufmann and Blum 2013). The concept of ecosystem reliability (Naeem 1998) addresses sensitivity (or resistance) properties, not vulnerability as a whole. Substantial fluctuations in service provision (as would be accepted within the concept of resilient systems) should be prevented.

\section{Adaptive Capacity of Ecosystems}

Adaptive capacity describes a system's ability to cope with the impact of a disturbance. In contrast to planned adaptation measures of a society or community, for natural systems the term autonomous adaptation appears (Metzger et al. 2006), emphasizing spontaneous ecological changes within the affected ecosystem. Therefore, the adaptation is self-organized by the ecosystem as a sum of responses of its biophysical entities. Although accounting for adaptive capacity is key in determining vulnerability, its characterization regarding natural systems is scarce (Okey et al. 2015).

The reviewed literature was scarce in descriptions of how to measure the adaptive capacity of a natural system. A few equaled it with a potential to recover, e.g., with a quick reproduction (number of seedlings produced per adult, number of juveniles per number of dead adults) from a mangrove forest (Ventura and Lana 2014), or with repopulation of a coral ecosystem with original species instead of leaving the field to competitors (Cinner et al. 2013). Others used the term resilience in a very similar meaning and tried to estimate it, for example, by the connectivity between ecosystems of the same type (Peng et al. 2015), the natural succession rate after a tsunami (Romer et al. 2012), the local vegetation cover (Zhang et al. 2015) or the local biodiversity in general (Song et al. 2015). Overall it seems that the adaptive capacity of ecosystems originates dominantly from the biological entities rather from the abiotic ecosystem components, but is hard to measure specifically. Therefore, the analysis of ecosystem adaptive capacity may be approached from the community of organisms and their interrelations. This would also include the ecological levels below a community of $\mathrm{sp}$ ecies: the adaptive capacity of single species, of single populations of these species, and even the capacity of individuals to adapt to a certain impact. Observations on the level of single plants indicate the existence of an ecological memory after drought, frost or heat stress, as their responses to such types of disturbances improved due to the stressors experienced. This supports the broader theory of ecological memory that refers to whole ecosystems and involves more than pure acclimatization or repopulation opportunities (Walter et al. 2013). On the species level, a high genetic differentiation within and between populations promotes adaptive capacity, which could differ between locations and along geographic distances (NWF 2011). Species respond according to their ability to maintain or enhance population quantity or to invade the disturbed environment afresh (Diaz et al. 2013). On the community level, this translates to a response diversity within a functional group of species (Elmqvist et al. 2003). A high adaptive capacity of plant communities would be governed in particular by species with a long-lived seed bank, ruderal strategy, and high regenerative and dispersion capacities (Van Looy et al. 2016). Similarly, the dispersal abilities of animal species (e.g., by migration) should be integrated to 
such a community assessment to better estimate the adaptive capacity of ecosystems.

\section{Coherent Concepts for Ecosystem Assessment}

The idea of vulnerability as a system's characteristic is interrelated to other applied concepts of global change science, like exposure, sensitivity, resilience, adaptive capacity, and adaptation (Smit and Wandel 2006). As exposure, sensitivity, and adaptive capacity are directly included in vulnerability according to our definition, two main concepts remain for comparison regarding theoretical coherence for ecosystem assessment. Regarding socioecological systems Adger (2006) stated common terminological and methodological ground for the three concepts of vulnerability, resilience, and adaptation. Building on this, we suggest that the ecosystem response to a stress or a disturbance ultimately can be described being either: (i) vulnerable, (ii) resilient, or (iii) adaptive (see Fig. 2). Still, this framework leaves the question of how to define the reference state of regular variation ahead of the disturbance/ stress (or the original basin of attraction). A high or low undisturbed variability would clearly influence the interpretation of the system response. The boundary between a vulnerable and a resilient response would be based on the lower level of regular variation, measured by a threshold value of the investigated state variable. The same is for the boundary between a resilient and an adaptive response regarding the upper level of regular variation.

When expanding the concept of vulnerability to ecosystems, the question arises of whether vulnerability is in coherence with other measures of assessing an ecosystem's

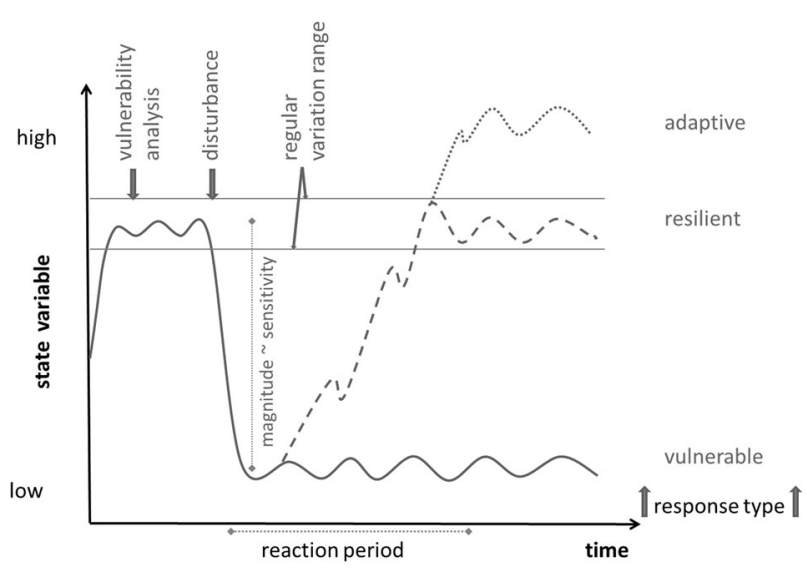

Fig. 2 Ecosystem response framework for coherently placing vulnerability analysis next to the concepts of resilience and adaptability. Source: Based on the disturbance concept by White and Jentsch (2001) response to a disturbance. Therefore, we sum up the specific relationship of vulnerability with the two closely related, established concepts of resilience and adaptability.

\section{Vulnerability and Resilience}

In the context of vulnerability, resilience arises as a general antithesis to vulnerability (Eakin and Luers 2006; Frazier et al. 2014; Kaufmann and Blum 2013). Vulnerability viewed as the opposite of resilience, is limited to the idea of coping and could profit from the natural science-driven perspective of resilience by understanding the responses to stressors (Renaud et al. 2010). Both vulnerability and resilience can be viewed as specific to a system and to a perturbation (Aretano et al. 2015).

Similar to ecosystem vulnerability, resilience is a dynamic indicator of ecosystem behavior following the occurrence of a disturbance. However, the concept of resilience was shaped in different schools of thought and the diversity of definitions leads to concurring or diverging meanings (Brand and Jax 2007; Fisichelli et al. 2016). Following the initial meaning of the word resilience (latin: resilire $=$ rebound, spring back), we would consider the concept in no conflict with ecosystem vulnerability (see Fig. 2). This meaning was preserved when ecological resilience was introduced that describes the ability of a system to return to a former attractor state after a disturbance has occurred (Gunderson and Holling 2002; Müller et al. 2010). In comparison, vulnerable ecosystems would experience a regime shift to a new, in anthropogenic view often unfavorable attractor state. This builds on the original idea introduced by Holling (1973) of using resilience to explain the persistence of species that show high population variance, which was understood to be detrimental to survival. The duration of the recovery phase is used as an indicator of the resilience of a system (engineering resilience, according to Pimm 1984). In other approaches (Walker et al. 2006; Walker et al. 2004), disturbance intensities reveal the load frame within which a system can react resiliently. For ecological resilience, Redman (2014) identified a tendency to judge outcomes that maintain the conditions of the pre-existing system as a positive result, although a resilient system could be in an undesirable state and may be improved by change. Members of the resilience-alliance (2014) forged an overarching meaning of resilience of socio-ecological systems that subsumes a self-organizing capacity, a resistance to disturbances or stresses and an evolutionary adaptation and learning process (Carpenter et al. 2001; Folke et al. 2003). Nevertheless, these added components actually reflect nonresilient processes (Fisichelli et al. 2016; Müller et al. 2016) and we suggest to stay with the more strict definition explained above. 


\section{Vulnerability and Adaptability}

The concept of adaptability was introduced to demonstrate that ecosystems follow certain optimization processes under undisturbed framework conditions in the succession process (Müller 1998), during which the values of selected variables (orientors, cf. Müller and Leupelt 1998) increase. In general, a natural entity maintains a dynamic response towards thermodynamic balance (Arreguin-Sanchez and RuizBarreiro 2014). If a system responds to a disturbance by recovering, the initial values of the state variables (e.g., biodiversity) can be exceeded, showing an adaptive response (see Fig. 2). This has similarities to the concept of ecological memory that leads to an improved response after several disturbances of the same type (cf. Walter et al. 2013).

Adaptability (or the ability for adaptation) has a similar meaning as or is closely related to adaptive capacity (Smit and Wandel 2006), and therefore seems to be compatible with the concept of vulnerability. Further, adaptive capacity in turn has been identified as a common thread linking vulnerability and resilience (Engle 2011).

\section{Operationalization of Ecosystem Vulnerability Assessments}

Decision-makers often have to prioritize options for action on the ground and can only use theoretical concepts of vulnerability to a limited extent (Luers 2005). Therefore, this review offers a straightforward assessment procedure as an-by no means exhaustive-outlook for application.

A site-specific ("place-based") reference to vulnerability seems indispensable (Cutter 1996). In contrast to supraregional considerations, place-specific studies map the individual specifics of vulnerability characteristics more effectively. This is particularly the case in the context of analysing ecosystem functions and regulatory processes in connection with biodiversity and nature protection (Metzger et al. 2006). Moreover, proximity relationships and cumulative ecological degradation effects could be taken into account due to spatial referencing (Jackson et al. 2004).

Therefore, a common approach to assessing a system's vulnerability is the overlap of spatial characteristics relating to a specific change or disturbance and summing them up in a vulnerability index (Frazier et al. 2014). Involving relatively little effort, index-based mapping enables a relatively wide range of factors to be considered compared to modeling. Vulnerability indices can be understood as systematically documented and transparent hypothesis frameworks that can be based on empirical data and expert opinions (Blatt et al. 2010). They can be applied as solution-oriented tools, evaluating scenarios and identifying trade-offs, rather than only assessing and monitoring existing conditions (Vollmer et al. 2016).

An index of ecosystem vulnerability should not be substantiated with general but stressor-specific environmental indicators that include information on exposure, sensitivity and the adaptive capacity of an ecosystem (Villa and McLeod 2002). Still, this entails difficult choices about the selection, standardization, weighting, and aggregation of indicators (Barnett et al. 2008). Possibly, the application of an analytical hierarchy process helps to create a weighted set of indicators in the GIS overlay procedure (e.g., Cai et al. 2015; Wang et al. 2015).

\section{Conclusions}

Applying the vulnerability analysis to natural systems creates new opportunities for efficient ecosystem assessment. It reveals the damage potential on the basis of a current constellation of factors and could function as an early warning system. We conclude that this ecosystem-oriented approach is still pioneering work compared to the overall vulnerability research and suggest using the term ecosystem vulnerability instead of environmental vulnerability (in parts interpreted as vulnerability to environmental factors) or ecological vulnerability (confused with research of socioecological systems that often investigate a coupled human-environment system suffering from a disturbance and responding to it). The terms population and community vulnerability would only be of comparable meaning in a strict ecological context. To not compromise the interdisciplinary application of the concept, in both cases we recommend strengthening the term ecosystem vulnerability, subsuming populations and communities of species under ecosystems.

Ecosystem vulnerability has been adopted most notably in conservation biology, climate change research and ERAs. Up to date, it has not significantly shaped the plenty of other research fields dealing with environmental impacts or ecosystem management. Marine and freshwater ecosystems are of major concern, followed by forest ecosystems, whereas agricultural or grassland ecosystems have rarely been considered so far.

The constituting elements ecosystem exposure, ecosystem sensitivity and ecosystem adaptive capacity can be defined consistently. Their more detailed description, deduced from the reviewed literature, underpins the theoretic basis of the ecosystem vulnerability concept.

A key advantage of the vulnerability concept is the coherence with resilience and adaptability as different kinds of ecosystem responses in combination with its function as a boundary object that potentially enables interdisciplinary exchange to better tackle complex problems, such as 
climate change and biodiversity loss. The creation of vulnerability indices is a straightforward option to efficiently implement the concept for ecosystem assessment and management.

Acknowledgements Peter Weißhuhn thanks for the receipt of a doctoral scholarship from the Deutsche Bundesstiftung Umwelt (DBU) in 2016/17.

\section{Compliance with Ethical Standards}

Conflict of Interest The authors declare that they have no conflict of interest.

Open Access This article is distributed under the terms of the Creative Commons Attribution 4.0 International License (http://crea tivecommons.org/licenses/by/4.0/), which permits unrestricted use, distribution, and reproduction in any medium, provided you give appropriate credit to the original author(s) and the source, provide a link to the Creative Commons license, and indicate if changes were made.

\section{References}

Abbasov RK, Smakhtin VU (2012) Indexing the environmental vulnerability of mountain streams in Azerbaijan. Mt Res Dev 32:73-82. https://doi.org/10.1659/mrd-journal-d-11-00012.1

Adger WN (2006) Vulnerability. Glob Environ Change 16:268-281. https://doi.org/10.1016/j.gloenvcha.2006.02.006

Agatz A, Hammers-Wirtz M, Gabsi F, Ratte HT, Brown CD, Preuss TG (2012) Promoting effects on reproduction increase population vulnerability of Daphnia magna. Environ Toxicol Chem 31:1604-1610. https://doi.org/10.1002/etc.1862

Alric B et al. (2013) Local forcings affect lake zooplankton vulnerability and response to climate warming. Ecology 94:2767-2780. https://doi.org/10.1890/12-1903.1

Anthony KRN et al. (2015) Operationalizing resilience for adaptive coral reef management under global environmental change. Glob Change Biol 21:48-61. https://doi.org/10.1111/gcb.12700

Aretano R, Semeraro T, Petrosillo I, De Marco A, Pasimeni MR, Zurlini G (2015) Mapping ecological vulnerability to fire for effective conservation management of natural protected areas. Ecol Model 295:163-175. https://doi.org/10.1016/j.ecolmodel. 2014.09.017

Arianoutsou M et al. (2013) 8 Comparative patterns of plant invasions in the mediterranean biome. PLos One. https://doi.org/10.1371/ journal.pone.0079174

Arreguin-Sanchez F, Ruiz-Barreiro TM (2014) Approaching a functional measure of vulnerability in marine ecosystems. Ecol Indic 45:130-138. https://doi.org/10.1016/j.ecolind.2014.04.009

Ateweberhan M, McClanahan TR, Graham NAJ, Sheppard CRC (2011) Episodic heterogeneous decline and recovery of coral cover in the Indian Ocean. Coral Reefs 30:739-752. https://doi. org/10.1007/s00338-011-0775-x

Barnett J, Lambert S, Fry I (2008) The hazards of indicators: insights from the environmental vulnerability index. Ann Assoc Am Geogr 98:102-119. https://doi.org/10.1080/00045600701734315

Birkmann J, Wisner B (2006) Measuring the unmeasurable: the challenge of vulnerability. Institute for Environment and Human Security, Bonn, vol No. 5/2006

Blatt J, Ellner B, Strixner L, Kreft S, Luthardt V, Ibisch PL (2010) Index-basierte Erfassung der Klimawandel-Vulnerabilität von
Wald- und Forstökosystemen im Nationalpark Unteres Odertal. Paper presented at the Biodiversität und Klima - Vernetzung der Akteure in Deutschland VII, Internationale Naturschutzakademie Insel Vilm

Brand FS, Jax K (2007) Focusing the meaning(s) of resilience: resilience as a descriptive concept and a boundary object. Ecol Soc 12(1):23. http://www.ecologyandsociety.org/vol12/iss1/art23/

Brooks N (2003) Vulnerability, risk and adaptation: a conceptual framework. Tyndall Centre Clim Change Res 38:1-16

Brussard PF, Reed JM, Tracy CR (1998) Ecosystem management: what is it really? Landsc Urban Plan 40:9-20. https://doi.org/10. 1016/S0169-2046(97)00094-7

Bürkner H-J (2010) Vulnerabilität und Resilienz - Forschungsstand und sozialwissenschaftliche Untersuchungsperspektiven. Working Paper, Erkner, Leibniz-Institut für Regionalentwicklung und Strukturplanung, 2010, http://www.irs-net.de/download/wp_vr.pdf

Cabral P et al. (2015) Marine habitats ecosystem service potential: a vulnerability approach in the Normand-Breton (Saint Malo) Gulf. Fr Ecosyst Serv 16:306-318. https://doi.org/10.1016/j.ecoser. 2014.09.007

Cai L, Yan L, Ni JL, Wang C (2015) Assessment of ecological vulnerability under oil spill stress Sustainability 7:13073-13084. https://doi.org/10.3390/su71013073

Caniani D, Lioi DS, Mancini IM, Masi S (2015) Hierarchical classification of groundwater pollution risk of contaminated sites using Fuzzy logic: a case study Basilicata region (Italy) Water 7:2013-2036. https://doi.org/10.3390/w7052013

Carpenter S, Walker B, Anderies JM, Abel N (2001) From metaphor to measurement: resilience of what to what? Ecosystems 4:765-781

Chapin FS, Walker BH, Hobbs RJ, Hooper DU, Lawton JH, Sala OE, Tilman D (1997) Biotic control over the functioning of ecosystems. Science 277:500-504. https://doi.org/10.1126/science.277. 5325.500

Chen S, Chen B, Fath BD (2013) Ecological risk assessment on the system scale: a review of state-of-the-art models and future perspectives. Ecol Model 250:25-33. https://doi.org/10.1016/j. ecolmodel.2012.10.015

Chu-Agor ML, Munoz-Carpena R, Kiker G, Emanuelsson A, Linkov I (2011) Exploring vulnerability of coastal habitats to sea level rise through global sensitivity and uncertainty analyses. Environ Model Softw 26:593-604. https://doi.org/10.1016/j.envsoft.2010. 12.003

Cinner JE et al. (2013) Evaluating social and ecological vulnerability of coral reef fisheries to climate change. PLoS One https://doi. org/10.1371/journal.pone.0074321

Collet D (2012) „Vulnerabilität“ als Brückenkonzept der Hungerforschung. In: Collet D, Lassen T, Schanbacher A (eds) Handeln in Hungerkrisen: neue Perspektiven auf soziale und klimatische Vulnerabilität. Universitätsverlag Göttingen, Göttingen, pp 13-26

Couto RD et al. (2015) Environmental vulnerability and phosphorus fractions of areas with pig slurry applied to the soil. J Environ Qual 44:162-173. https://doi.org/10.2134/jeq2014.08.0359

Cruz-Elizalde R, Ramirez-Bautista A, Johnson JD, Moreno CE (2014) Community structure of reptiles from the southern portion of the Chihuahuan Desert Region, Mexico. North-West J Zool 10:173-182

Cruz-Elizalde R, Ramirez-Bautista A, Wilson LD, Hernandez-Salinas U (2015) Effectiveness of protected areas in herpetofaunal conservation in Hidalgo, Mexico. Herpetol J 25:41-48

Cutter SL (1996) Vulnerability to environmental hazards. Prog Hum Geogr 20:529-539

Daily GC (1997) Nature's services: societal dependence on natural ecosystems. Island Press, Washington

De Lange HJ, Sala S, Vighi M, Faber JH (2010) Ecological vulnerability in risk assessment-a review and perspectives. Sci Total 
Environ 408:3871-3879. https://doi.org/10.1016/j.scitotenv. 2009.11.009

Diaz S et al. (2013) Functional traits, the phylogeny of function, and ecosystem service vulnerability. Ecol Evol 3:2958-2975. https:// doi.org/10.1002/ece3.601

Dong $\mathrm{Z}$ et al. (2015) A novel method for quantitatively evaluating agricultural vulnerability to climate change. Ecol Indic 48:49-54. https://doi.org/10.1016/j.ecolind.2014.07.032

Drever MC, Clark RG, Derksen C, Slattery SM, Toose P, Nudds TD (2012) Population vulnerability to climate change linked to timing of breeding in boreal ducks. Glob Change Biol 18:480-492. https://doi.org/10.1111/j.1365-2486.2011.02541.x

Dufresnes C, Perrin N (2015) Effect of biogeographic history on population vulnerability in European amphibians. Conserv Biol 29:1235-1241. https://doi.org/10.1111/cobi.12490

Eakin H, Luers AL (2006) Assessing the vulnerability of socialenvironmental systems. Annu Rev Environ Resour 31:365-394. https://doi.org/10.1146/annurev.energy.30.050504.144352

Elmqvist T, Folke C, Nyström M, Peterson G, Bengtsson J, Walker B, Norberg J (2003) Response diversity, ecosystem change, and resilience. Front Ecol Environ 1:488-494

Engle NL (2011) Adaptive capacity and its assessment Glob Environ Change 21:647-656. https://doi.org/10.1016/j.gloenvcha.2011. 01.019

Erickson RA, Eager EA, Stanton JC, Beston JA, Diffendorfer JE, Thogmartin WE (2015) Assessing local population vulnerability with branching process models: an application to wind energy development. Ecosphere. https://doi.org/10.1890/es15-00103.1

Fisichelli NA, Schuurman GW, Hoffman CH (2016) Is 'Resilience' maladaptive? Towards an accurate lexicon for climate change adaptation. Environ Manage 57:753-758. https://doi.org/10.1007/ s00267-015-0650-6

Folke C, Colding J, Berkes F (2003) Synthesis: building resilience and adaptive capacity in social-ecological systems. In: Berkes F, Colding J, Folke C (eds) Navigating social-ecological systems: building resilience for complexity and change. Cambridge University Press, Cambridge, pp 352-387

Frazier TG, Thompson CM, Dezzani RJ (2014) A framework for the development of the SERV model: a spatially explicit resiliencevulnerability model. Appl Geogr 51:158-172. https://doi.org/10. 1016/j.apgeog.2014.04.004

Furness RW, Wade HM, Robbins AMC, Masden EA (2012) Assessing the sensitivity of seabird populations to adverse effects from tidal stream turbines and wave energy devices. Ices J Mar Sci 69:1466-1479. https://doi.org/10.1093/icesjms/fss131

Füssel H-M (2007) Vulnerability: A generally applicable conceptual framework for climate change research. Glob Environ Change 17:155-167. https://doi.org/10.1016/j.gloenvcha.2006.05.002

Gauthier P, Foulon Y, Jupille O, Thompson JD (2013) Quantifying habitat vulnerability to assess species priorities for conservation management. Biol Conserv 158:321-325. https://doi.org/10. 1016/j.biocon.2012.08.012

Gergs A, Zenker A, Grimm V, Preuss TG (2013) Chemical and natural stressors combined: from cryptic effects to population extinction. Sci Rep. https://doi.org/10.1038/srep02036

Giakoumi S, Brown CJ, Katsanevakis S, Saunders MI, Possingham HP (2015) Using threat maps for cost-effective prioritization of actions to conserve coastal habitats. Mar Pol 61:95-102. https:// doi.org/10.1016/j.marpol.2015.07.004

Gonzalez-Moreno P, Pino J, Gasso N, Vila M (2013) Landscape context modulates alien plant invasion in Mediterranean forest edges. Biol Invasions 15:547-557. https://doi.org/10.1007/ s10530-012-0306-x

Guizien K, Belharet M, Moritz C, Guarini JM (2014) Vulnerability of marine benthic metapopulations: implications of spatially structured connectivity for conservation practice in the Gulf of Lions
(NW Mediterranean Sea). Divers Distrib 20:1392-1402. https:// doi.org/10.1111/ddi.12254

Gunderson LH, Holling CS (eds) (2002) Panarchy: understanding transformations in human and natural systems. Island Press, Washington Covelo

Holling CS (1973) Resilience and stability of ecological systems. Annu Rev Ecol Syst 4:1-23. https://doi.org/10.2307/2096802

Hulme PE (2012) Weed risk assessment: a way forward or a waste of time? J Appl Ecol 49:10-19. https://doi.org/10.1111/j.1365-2664. 2011.02069.x

Hwang T, Band LE, Miniat CF, Song CH, Bolstad PV, Vose JM, Love JP (2014) Divergent phenological response to hydroclimate variability in forested mountain watersheds. Glob Change Biol 20:2580-2595. https://doi.org/10.1111/gcb.12556

Ibisch PL, Hobson P (eds) (2014) MARISCO. Adaptive management of vulnerability and risk at conservation sites. In: A guidebook for risk-robust, adaptive and ecosystem-based conservation of biodiversity. Centre for Econics and Ecosystem Management, Eberswalde

Ifrim C, Gotz S, Stinnesbeck W (2011) Fluctuations of the oxygen minimum zone at the end of Oceanic Anoxic Event 2 reflected by benthic and planktic fossils. Geology 39:1043-1046. https://doi. org/10.1130/g32161.1

IPCC (2007) Assessing key vulnerabilities and the risk from climate change. In: Parry ML, Canziani OF, Palutikof JP, van der Linden PJ, Hanson CE (eds) Climate change 2007: impacts, adaptation and vulnerability. Contribution of Working Group II to the fourth assessment report of the Intergovernmental Panel on Climate Change, vol 4. Cambridge, Cambridge University Press, pp $779-810$

IPCC (2014) Emergent risks and key vulnerabilities. In: Field CB et al. (ed) Climate change 2014: impacts, adaptation, and vulnerability. Working Group II Contribution to the fifth assessment report of the Intergovernmental Panel on climate change, vol Part A: global and sectoral aspects. Cambridge University Press, New York

Ippolito A, Sala S, Faber JH, Vighi M (2010) Ecological vulnerability analysis: a river basin case study. Sci Total Environ 408:3880-3890. https://doi.org/10.1016/j.scitotenv.2009.10.002

Ippolito A, Todeschini R, Vighi M (2012) Sensitivity assessment of freshwater macroinvertebrates to pesticides using biological traits. Ecotoxicology 21:336-352. https://doi.org/10.1007/ s10646-011-0795-x

Jackson LE, Bird SL, Matheny RW, O'Neill RV, White D, Boesch $\mathrm{KC}$, Koviach JL (2004) A regional approach to projecting landuse change and resulting ecological vulnerability. Environ Monit Assess 94:231-248

Janssen MA, Schoon ML, Ke W, Börner K (2006) Scholarly networks on resilience, vulnerability and adaptation within the human dimensions of global environmental change. Glob Environ Change 16:240-252

Kalusova V, Chytry M, Kartesz JT, Nishino M, Pysek P (2013) Where do they come from and where do they go? European natural habitats as donors of invasive alien plants globally. Divers Distrib 19:199-214. https://doi.org/10.1111/ddi.12008

Kaly U, Pratt C, Mitchell DJ (2004) The demonstration environmental vulnerability index. South Pacific Applied Geoscience Commission, Suva, Fiji, (EVI) vol 384

Kaufmann S, Blum S (2013) Vulnerabilität und Resilienz: Zum Wandern von Ideen in der Umwelt- und Sicherheitsdiskussion. In: Detten Rv, Faber F, Bemmann M (eds) Unberechenbare Umwelt: Zum Umgang mit Unsicherheit und Nicht-Wissen. Springer, Wiesbaden, pp 91-120. https://doi.org/10.1007/978-3531-94223-0_6

Kulkarni D, Hommen U, Schaffer A, Preuss TG (2014) Ecological interactions affecting population-level responses to chemical 
stress in Mesocyclops leuckarti. Chemosphere 112:340-347. https://doi.org/10.1016/j.chemosphere.2014.04.062

Lacasella F, Gratton C, De Felici S, Isaia M, Zapparoli M, Marta S, Sbordoni V (2015) Asymmetrical responses of forest and "beyond edge" arthropod communities across a forest-grassland ecotone. Biodivers Conserv 24:447-465. https://doi.org/10.1007/ s10531-014-0825-0

Landguth EL et al. (2014) Combining demographic and genetic factors to assess population vulnerability in stream species. Ecol Appl 24:1505-1524

Leslie HM, McLeod KL (2007) Confronting the challenges of implementing marine ecosystem-based management. Front Ecol Environ 5:540-548. https://doi.org/10.1890/060093

Lopez-Poma R, Orr BJ, Bautista S (2014) Successional stage after land abandonment modulates fire severity and post-fire recovery in a Mediterranean mountain landscape. Int $\mathrm{J}$ Wildland Fire 23:1005-1015. https://doi.org/10.1071/wf13150

Luers AL (2005) The surface of vulnerability: an analytical framework for examining environmental change. Glob Environ Change 15:214-223. https://doi.org/10.1016/j.gloenvcha.2005.04.003

Macary F, Morin S, Probst JL, Saudubray F (2014) A multi-scale method to assess pesticide contamination risks in agricultural watersheds. Ecol Indic 36:624-639. https://doi.org/10.1016/j. ecolind.2013.09.001

McWethy DB et al. (2013) A conceptual framework for predicting temperate ecosystem sensitivity to human impacts on fire regimes. Glob Ecol Biogeogr 22:900-912. https://doi.org/10. 1111/geb. 12038

Metzger MJ, Rounsevell MDA, Acosta-Michlik L, Leemans R, Schröter D (2006) The vulnerability of ecosystem services to land use change. Agric Ecosyst Environ 114:69-85. https://doi.org/10. 1016/j.agee.2005.11.025

Moe SJ, De Schamphelaere K, Clements WH, Sorensen MT, Van den Brink PJ, Liess M (2013) Combined and interactive effects of global climate change and toxicants on populations and communities. Environ Toxicol Chem 32:49-61. https://doi.org/10. 1002/etc. 2045

Müller F (1998) Gradients in ecological systems. Ecol Model 108:3-21

Müller F et al. (2016) Assessing resilience in long-term ecological data sets. Ecol Indic 65:10-43. https://doi.org/10.1016/j.ecolind.2015. 10.066

Müller F, Burkhard B, Kroll F (2010) Resilience, integrity and ecosystem dynamics: bridging ecosystem theory and management. In: Otto J-C, Dikau R (eds) Landform-structure, evolution, process control, vol 115. Lecture Notes in Earth Sciences. Springer, Berlin Heidelberg, pp 221-242. https://doi.org/10.1007/ 978-3-540-75761-0_14

Müller F, Leupelt M (eds) (1998) Eco targets, goal functions, and orientors. Springer, Berlin Heidelberg [u.a.]

Munson SM et al. (2015) Long-term plant responses to climate are moderated by biophysical attributes in a North American desert. J Ecol 103:657-668. https://doi.org/10.1111/1365-2745.12381

Naeem S (1998) Species redundancy and ecosystem reliability. Conserv Biol 12:39-45. https://doi.org/10.1111/j.1523-1739.1998. 96379.x

NWF (2011) Scanning the conservation horizon: a guide to climate change vulnerability assessment. National Wildlife Foundation, Washington DC

Okey TA, Agbayani S, Alidina HM (2015) Mapping ecological vulnerability to recent climate change in Canada's Pacific marine ecosystems. Ocean Coast Manage 106:35-48. https://doi.org/10. 1016/j.ocecoaman.2015.01.009

Olden JD, Vander Zanden MJ, Johnson PTJ (2011) Assessing ecosystem vulnerability to invasive rusty crayfish (Orconectes rusticus). Ecol Appl 21:2587-2599
Pei H, Fang SF, Lin L, Qin ZH, Wang XY (2015) Methods and applications for ecological vulnerability evaluation in a hyperarid oasis: a case study of the Turpan Oasis, China. Environ Earth Sci 74:1449-1461. https://doi.org/10.1007/s12665-0154134-Z

Peng J, Zong ML, Hu YN, Liu YX, Wu JS (2015) Assessing landscape ecological risk in a Mining City: a case study in Liaoyuan City, China. Sustainability 7:8312-8334. https://doi.org/10.3390/ su7078312

Pimm SL (1984) The complexity and stability of ecosystems. Nature 307:321-326. https://doi.org/10.1038/307321a0

Pinedo J, Ibanez R, Primo O, Gomez P, Irabien A (2014) Preliminary assessment of soil contamination by hydrocarbon storage activities: main site investigation selection. $\mathrm{J}$ Geochem Explor 147:283-290. https://doi.org/10.1016/j.gexplo.2014.03.016

Polsky C, Neff R, Yarnal B (2007) Building comparable global change vulnerability assessments: The vulnerability scoping diagram. Glob Environ Change 17:472-485. https://doi.org/10.1016/j. gloenvcha.2007.01.005

Qiao Z, Yang X, Liu J, Xu XL (2013) Ecological vulnerability assessment integrating the spatial analysis technology with algorithms: a case of the wood-grass ecotone of Northeast China. Abstr Appl Anal 2013:263-268. https://doi.org/10.1155/2013/ 207987

Redman CL (2014) Should sustainability and resilience be combined or remain distinct pursuits. Ecol Soc 19:37

Renaud FG, Birkmann J, Damm M, Gallopín GC (2010) Understanding multiple thresholds of coupled social-ecological systems exposed to natural hazards as external shocks. Nat Hazards 55:749-763. https://doi.org/10.1007/s11069-010-9505-x

Resilience-Alliance (2014) Key concepts. http://www.resalliance.org/ index.php/key_concepts. Accessed 6 Sept 2014

Romer H, Willroth P, Kaiser G, Vafeidis AT, Ludwig R, Sterr H, Diez JR (2012) Potential of remote sensing techniques for tsunami hazard and vulnerability analysis - a case study from Phang-Nga province. Thail Nat Hazards Earth Syst Sci 12:2103-2126. https://doi.org/10.5194/nhess-12-2103-2012

Rosenfeld JS (2002) Functional redundancy in ecology and conservation. Oikos 98:156-162. https://doi.org/10.1034/j.16000706.2002.980116.x

Schluchter W (2002) Vulnerabilität—interdisziplinär. Paper presented at the Zweites Forum Katastrophenvorsorge. Extreme Naturereignisse-Folgen, Vorsorge, Werkzeuge., Leipzig, pp. 24-26. Sept 2001

Schröter D, Polsky C, Patt AG (2005) Assessing vulnerabilities to the effects of global change: an eight step approach. Mitig Adapt Strateg Glob Change 10:573-595

SCImago (2007) SJR - SCImago journal \& country rank. Scimago Lab. http://www.scimagojr.com. Accessed 21 July 2015

Simoncini R (2011) Governance objectives and instruments, ecosystem management and biodiversity conservation: the Chianti case study. Reg Environ Change 11:29-44. https://doi.org/10.1007/ s10113-010-0112-x

Slocombe DS (1993) Implementing ecosystem-based management. Bioscience 43:612-622. https://doi.org/10.2307/1312148

Smit B, Wandel J (2006) Adaptation, adaptive capacity and vulnerability. Glob Environ Change 16:282-292. https://doi.org/10. 1016/j.gloenvcha.2006.03.008

Song GB, Li Z, Yang YG, Semakula HM, Zhang SS (2015) Assessment of ecological vulnerability and decision-making application for prioritizing roadside ecological restoration: a method combining geographic information system, Delphi survey and Monte Carlo simulation. Ecol Indic 52:57-65. https://doi.org/10.1016/j. ecolind.2014.11.032

Tomczyk AM (2011) A GIS assessment and modelling of environmental sensitivity of recreational trails: the case of Gorce National 
Park, Poland. Appl Geogr 31:339-351. https://doi.org/10.1016/j. apgeog.2010.07.006

Tranquilla LAM et al. (2013) Multiple-colony winter habitat use by murres Uria spp. in the Northwest Atlantic Ocean: implications for marine risk assessment. Mar Ecol Prog Ser 472:287-303. https://doi.org/10.3354/meps10053

Trumbo BA et al. (2014) Ranking site vulnerability to increasing temperatures in southern appalachian brook trout streams in Virginia: an exposure-sensitivity approach. Trans Am Fish Soc 143:173-187. https://doi.org/10.1080/00028487.2013.835282

Turner II BL et al. (2003) A framework for vulnerability analysis in sustainability science. Proc Natl Acad Sci 100:8074-8079. https://doi.org/10.1073/pnas.1231335100

Ursino N (2014) Eco-hydrology driven fire regime in savanna. J Theor Biol 355:68-76. https://doi.org/10.1016/j.jtbi.2014.04.002

van Gestel CAM (2012) Soil ecotoxicology: state of the art and future directions. Zookeys 176:275-296. https://doi.org/10.3897/ zookeys.176.2275

Van Looy K, Lejeune M, Verbeke W (2016) Indicators and mechanisms of stability and resilience to climatic and landscape changes in a remnant calcareous grassland. Ecol Indic 70:498-506

Ventura ADB, Lana PD (2014) A new empirical index for assessing the vulnerability of peri-urban mangroves. J Environ Manage 145:289-298. https://doi.org/10.1016/j.jenvman.2014.04.036

Vigneron A, Geffard O, Coquery M, Francois A, Queau H, Chaumot A (2015) Evolution of cadmium tolerance and associated costs in a Gammarus fossarum population inhabiting a low-level contaminated stream. Ecotoxicology 24:1239-1249. https://doi.org/ 10.1007/s10646-015-1491-z

Villa F, McLeod H (2002) Environmental vulnerability indicators for environmental planning and decision-making: guidelines and applications. Environ Manage 29:335-348. https://doi.org/10. 1007/s00267-001-0030-2

Vollmer D, Regan HM, Andelman SJ (2016) Assessing the sustainability of freshwater systems: a critical review of composite indicators. Ambio 45:765-780. https://doi.org/10.1007/s13280016-0792-7

Walker B, Gunderson LH, Kinzig A, Folke C, Carpenter S, Schultz L (2006) A handful of heuristics and some propositions for understanding resilience in social-ecological systems. Ecol Soc 11(1): 13

Walker B, Holling CS, Carpenter SR, Kinzig A (2004) Resilience, adaptability and transformability in social-ecological systems. Ecol Soc 9(2):5
Walker BH (1992) Biodiversity and ecological redundancy. Conserv Biol 6:18-23. https://doi.org/10.1046/j.1523-1739.1992.610018.x

Walter J, Jentsch A, Beierkuhnlein C, Kreyling J (2013) Ecological stress memory and cross stress tolerance in plants in the face of climate extremes. Environ Exp Bot 94:3-8. https://doi.org/10. 1016/j.envexpbot.2012.02.009

Wang Y, Ding Q, Zhuang DF (2015) An eco-city evaluation method based on spatial analysis technology: a case study of Jiangsu Province, China. Ecol Indic 58:37-46. https://doi.org/10.1016/j. ecolind.2015.05.032

Watson JEM, Iwamura T, Butt N (2013) Mapping vulnerability and conservation adaptation strategies under climate change. Nat Clim Change 3:989-994. https://doi.org/10.1038/nclimate2007

Weichselgartner J (2001) Naturgefahren als soziale Konstruktion. Dissertation, Rheinische Friedrich-Wilhelms-Universität Bonn

White PS, Jentsch A (2001) The search for generality in studies of disturbance and ecosystem dynamics. In: Esser K, Lüttge U, Kadereit JW, Beyschlag W (eds) Progress in botany, vol 62. Springer, Berlin Heidelberg, pp 399-450. https://doi.org/10.1007/ 978-3-642-56849-7_17

Williams LRR, Kapustka LA (2000) Ecosystem vulnerability: a complex interface with technical components. Environ Toxicol Chem 19:1055-1058

Wisner B, Blaikie P, Cannon T, Davis I (2004) At risk: natural hazards, people's vulnerability and disasters. edn 2, London, New York, Routledge

Zabeo A, Pizzol L, Agostini P, Critto A, Giove S, Marcomini A (2011) Regional risk assessment for contaminated sites Part 1: vulnerability assessment by multicriteria decision analysis. Environ Int 37:1295-1306. https://doi.org/10.1016/j.envint.2011.05.005

Zhang XR, Wang ZB, Lin J (2015) GIS based measurement and regulatory zoning of urban ecological vulnerability. Sustainability 7:9924-9942. https://doi.org/10.3390/su7089924

Zolkos SG, Jantz P, Cormier T, Iverson LR, McKenney DW, Goetz SJ (2015) Projected tree species redistribution under climate change: implications for ecosystem vulnerability across protected areas in the Eastern United States. Ecosystems 18:202-220. https://doi. org/10.1007/s10021-014-9822-0

Zurlini G, Amadio V, Rossi O (1999) A landscape approach to biodiversity and biological health planning: the map of Italian nature. Ecosyst Health 5:294-311. https://doi.org/10.1046/j.1526-0992. 1999.09948.x 